\title{
Draft Genome Sequence of Sphingobium sp. Strain C100, a Polycyclic Aromatic Hydrocarbon-Degrading Bacterium from the Deep-Sea Sediment of the Arctic Ocean
}

\author{
Chunming Dong, ${ }^{a, b, c}$ Xiuhua Bai, ${ }^{a, b, c}$ Qiliang Lai, ${ }^{a, b, c}$ Yanrong Xie, ${ }^{a, b, c, d}$ Xin Chen, ${ }^{a, b, c, d}$ Zongze Shao ${ }^{a, b, c}$ \\ Key Laboratory of Marine Genetic Resources, Third Institute of Oceanography, State Oceanic Administration, Xiamen, Chinaa; State Key Laboratory Breeding Base of \\ Marine Genetic Resources, Xiamen, Chinab; Key Laboratory of Marine Genetic Resources of Fujian Province, Xiamen, Chinac; Life Science College, Xiamen University, \\ Xiamen, Fujian, China ${ }^{d}$
}

Sphingobium sp. strain C100 was isolated from a polycyclic aromatic hydrocarbon (PAH)-degrading consortium from the deepsea sediment of the Arctic Ocean. It can degrade two- to four-ring PAHs at $25^{\circ} \mathrm{C}$. Here we present the draft genome sequence of this strain, which is $4,776,810$ bp with a $\mathrm{G}+\mathrm{C}$ content of $63.9 \%$.

Received 12 December 2013 Accepted 31 December 2013 Published 30 January 2014

Citation Dong C, Bai X, Lai Q, Xie Y, Chen X, Shao Z. 2014. Draft genome sequence of Sphingobium sp. strain C100, a polycyclic aromatic hydrocarbon-degrading bacterium from the deep-sea sediment of the Arctic Ocean. Genome Announc. 2(1):e01210-13. doi:10.1128/genomeA.01210-13.

Copyright $\odot 2014$ Dong et al. This is an open-access article distributed under the terms of the Creative Commons Attribution 3.0 Unported license.

Address correspondence to Zongze Shao, shaozz@163.com

$\mathrm{M}$ embers of the Sphingobium genus are Gram-negative, nonsporulating, rod-shaped aerobic bacteria with yellow or whitish-brown colonies (1). They have been isolated from a wide variety of environments and show the ability to degrade many kinds of xenobiotics, such as aromatic and chloroaromatic compounds (2-4). Here, we present the draft genome sequence of a Sphingobium bacterium, strain C100. The bacterium was isolated from a polycyclic aromatic hydrocarbon (PAH)degrading consortium, which was enriched from the deep-sea sediment of the Makarov Basin $\left(170^{\circ} 29^{\prime} \mathrm{W}, 87^{\circ} 04^{\prime} \mathrm{N}\right.$; water depth of $4,000 \mathrm{~m}$ ) in the Arctic Ocean, using a PAH mixture of naphthalene, phenanthrene, and pyrene as the sole carbon and energy source. Our previous studies indicated that this strain could degrade naphthalene, 2-methyl naphthalene, fluorene, acenaphthene, phenanthrene, anthracene, and fluoranthene at $25^{\circ} \mathrm{C}$ (unpublished data).

Genomic DNA was purified from strain C100 with an AxyPrep bacterial genomic DNA miniprep kit (Axygen) according to the manual instructions. The genome was sequenced using the Genome Analyzer IIx system at Shanghai Majorbio Biopharm Technology Co., Ltd. (Shanghai, China), which produced $955 \mathrm{Mbp}$ paired-end reads of $80 \mathrm{bp}$ with an insert size of $300 \mathrm{bp}$. Approximately 753-Mbp high-quality reads were assembled with SOAPdenovo v 1.05 (5). The final genome assembly has 157 -fold coverage and contains 219 scaffolds composed of 170 contigs (longer than $1,000 \mathrm{bp}$ ) with a total size of $4,776,810 \mathrm{bp}$, an $N_{50}$ contig length of $46,449 \mathrm{bp}$, and a mean $\mathrm{G}+\mathrm{C}$ content of $63.9 \%$.

Gene prediction and annotation of the draft genome were carried out using the NCBI Prokaryotic Genome Annotation Pipeline (PGAP) (http://www.ncbi.nlm.nih.gov/genomes/static /Pipeline.html) (6). In total, 4,634 genes were predicted, 4,513 of which are protein-coding genes, and 61 RNAs; 60 pseudogenes were also identified. The majority of the protein-coding genes $(3,268,70.5 \%)$ were assigned a putative function, while the re- maining ones were annotated as hypothetical proteins. In addition, a clustered regularly interspaced short palindromic repeat (CRISPR) array was found in the draft genome.

We particularly analyzed genes possibly responsible for the degradation of PAHs. At least 2 naphthalene 1,2-dioxygenase (7, 8), 6 aromatic-ring-hydroxylating dioxygenase (9), and 12 ferredoxin-related coding genes, which are responsible for the first catalytic reaction of PAH degradation (10), were found in the draft genome. During the degradation of PAHs, catechol, protocatechuate, gentisate, benzoate, and phthalate are the important intermediate metabolites (10). Congruently, one catechol 2,3dioxygenase, two protocatechuate 3,4-dioxygenase, three protocatechuate 4,5-dioxygenase, one gentisate 1,2-dioxygenase, and two benzoate 1,2-dioxygenase genes and one phthalate 4,5dioxygenase gene were also found in the genome. In addition, six cytochrome $\mathrm{P} 450$ genes were present in the genome. A previous study demonstrated that cytochrome P450 was involved in the degradation of PAHs (11). The genome sequence of Sphingobium sp. strain $\mathrm{C} 100$ will be helpful in understanding the PAHdegrading mechanism of the Sphingobium species.

Nucleotide sequence accession number. The annotated draft genome sequence was deposited in DDBJ/EMBL/GenBank under accession no. AYOY00000000. The version described in this paper is the first version.

\section{ACKNOWLEDGMENTS}

This work was financially supported by the Scientific Research Foundation of the Third Institute of Oceanography, SOA (2011), the National Natural Science Foundation of China (41206158), the Public Welfare Project of SOA (201005032), the Young Marine Science Foundation of SOA (2012142), and the China Polar Environment Investigation and Estimate Project (2012-2015).

We thank the whole team of the fourth Arctic research expedition of the "Xuelong" icebreaker. 


\section{REFERENCES}

1. Takeuchi M, Hamana K, Hiraishi A. 2001. Proposal of the genus Sphingomonas sensu stricto and three new genera, Sphingobium, Novosphingobium and Sphingopyxis, on the basis of phylogenetic and chemotaxonomic analyses. Int. J. Syst. Evol. Microbiol. 51:1405-1417. http://ijs.sgmjournals.org/content/51/4/1405.long.

2. Kertesz MA, Kawasaki A. 2010. Hydrocarbon-degrading sphingomonads: Sphingomonas, Sphingobium, Novosphingobium, and Sphingopyxis, p 1693-1705. In Timmis K (ed), Handbook of hydrocarbon and lipid microbiology. Springer Verlag, Heidelberg, Germany.

3. Wittich RM, Busse HJ, Kämpfer P, Tiirola M, Wieser M, Macedo AJ, Abraham WR. 2007. Sphingobium aromaticiconvertens sp. nov., a xenobioticcompound-degrading bacterium from polluted river sediment. Int. J. Syst. Evol. Microbiol. 57:306-310. http://dx.doi.org/10.1099/ijs.0.64433-0.

4. Niharika N, Sangwan N, Ahmad S, Singh P, Khurana JP, Lal R. 2013. Draft genome sequence of Sphingobium chinhatense strain IP26T, isolated from a hexachlorocyclohexane dumpsite. Genome Announc. 1(4): e00680-13. http://dx.doi.org/10.1128/genomeA.00680-13.

5. Luo R, Liu B, Xie Y, Li Z, Huang W, Yuan J, He G, Chen Y, Pan Q, Liu Y, Tang J, Wu G, Zhang H, Shi Y, Liu Y, Yu C, Wang B, Lu Y, Han C, Cheung DW, Yiu SM, Peng S, Xiaoqian Z, Liu G, Liao X, Li Y, Yang H, Wang J, Lam TW, Wang J. 2012. SOAPdenovo2: an empirically improved memory-efficient short-read de novo assembler. Gigascience 1:18. http://dx.doi.org/10.1186/2047-217X-1-18.
6. Angiuoli SV, Gussman A, Klimke W, Cochrane G, Field D, Garrity G, Kodira CD, Kyrpides N, Madupu R, Markowitz V, Tatusova T, Thomson N, White O. 2008. Toward an online repository of Standard Operating Procedures (SOPs) for (meta)genomic annotation. OMICS 12: 137-141. http://dx.doi.org/10.1089/omi.2008.0017.

7. Kauppi B, Lee K, Carredano E, Parales RE, Gibson DT, Eklund H, Ramaswamy S. 1998. Structure of an aromatic-ring-hydroxylating dioxygenase-naphthalene 1,2-dioxygenase. Structure 6:571-586. http: //dx.doi.org/10.1016/S0969-2126(98)00059-8.

8. Barriault D, Sylvestre M. 1999. Catalytic activity of Pseudomonas putida strain G7 naphthalene 1,2-dioxygenase on biphenyl. Int. Biodeterior. Biodegradation 44:33-37. http://dx.doi.org/10.1016/S0964-830 5(99)00049-9.

9. Parales RE, Resnick SM. 2006. Aromatic ring hydroxylating dioxygenases, p 287-340. In Ramos J-L, Levesque R (ed), Pseudomonas, vol 4. Springer, Berlin, Germany.

10. Fuchs G, Boll M, Heider J. 2011. Microbial degradation of aromatic compounds-from one strategy to four. Nat. Rev. Microbiol. 9:803-816. http://dx.doi.org/10.1038/nrmicro2652.

11. Brezna B, Kweon O, Stingley RL, Freeman JP, Khan AA, Polek B, Jones RC, Cerniglia CE. 2006. Molecular characterization of cytochrome P450 genes in the polycyclic aromatic hydrocarbon degrading Mycobacterium vanbaalenii PYR-1. Appl. Microbiol. Biotechnol. 71:522-532. http://dx .doi.org/10.1007/s00253-005-0190-8. 